\title{
POLÍTICAS PÚBLICAS E DESENVOLVIMENTO LOCAL EM ANGOLA, SUA INFLUÊNCIA NA VIDA DO CIDADÃO
}

\author{
Public policies and local development in Angola, its influence on citizens' lives
}

\begin{abstract}
Resumo
O presente estudo permite desenvolver uma reflexão em torno das políticas públicas e desenvolvimento local em Angola, seu impacto na vida do cidadão, a luz da metodologia qualitativa. Trata-se, no entanto, de um estudo resultante da área de investigação em Sociologia Política e Políticas Públicas, na Escola Superior Politécnica de Malanje. Em termos de teoria de suporte, optou-se pelo Funcionalismo, uma vez que a sociedade tem necessidades e, tal como um organismo, se essas necessidades não forem satisfeitas ela entrará em colapso. Por conseguinte, invoca-se neste artigo a inclusão do cidadão no processo de elaboração das políticas públicas, optando-se então por um modelo de políticas públicas de Baixo para Cima, bem como um modelo de governação baseado na descentralização administrativa e que responda as reais necessidades dos cidadãos. Os resultados obtidos mostram que o desenvolvimento local em Angla depende não só do tipo de liderança, mas também do tipo de políticas públicas que são elaboradas. Por outra, o fraco investimento nas comunidades locais, concorre para o despovoamento das mesmas e, por conseguinte, o superpovoamento dos centros urbanos, acarretando consigo graves problemas de saneamento básico e outras calamidades. A municipalização dos serviços públicos é a melhor estratégia para a solução dos problemas sociais que assolam os cidadãos.
\end{abstract}

\begin{abstract}
The present study allows us to develop a reflection on public policies and local development in Angola, its impact on the lives of citizens, in the light of qualitative methodology. It is, however, a study in the area of research in Political Sociology and Public Policies, at the Escola Superior Politécnica de Malanje. In terms of supporting theory, opt for Functionalism, since society has needs and, as an organism, if those requirements are no longer satisfied and collapse. For example, refer to this article and include a citizen in the public policy making process, then opting for a public policy model from the bottom up, as well as a governance model based on administrative decentralization and which responds as real citizens' needs. The results presented show that local development in English depends not only on the type of leadership, but also on the type of public policies that are developed. On the other hand, the low investment in local communities, occurs for the depopulation of them and, as a consequence, or the overpopulation of urban centers, such as tracking serious problems of basic sanitation and other calamities. The municipalization of public services is the best strategy for solving social problems that affect citizens.
\end{abstract}

Palavras-chave: Política; Política pública; Desenvolvimento local; Municipalização.

Keywords: Politics; Public polic; Local development; Municipalization.

Data de submissão: março de 2020 | Data de publicação: junho de 2020.

${ }^{1}$ HONÓRIO SALVADOR PEDRO SANTANA - Escola Superior Politécnica de Malanje. ANGOLA. E-mail: honox17santana@gmail.com 


\section{INTRODUÇÃO}

Angola é um Estado Soberano Democrático de Direito, onde o poder dos governantes emana do consentimento dos governados. É um Estado rico em recursos naturais e minerais, mas também um país com um baixo índice de desenvolvimento humano e elevada pobreza extrema.

Ora, sabendo do potencial em termos de recursos naturais e minerais, só para citar estes, não se entende por que razão o país continua a figurar no grupo de países com maior índice de pobreza, mortes, entre outras calamidades, tornando-o num dos países subdesenvolvidos do continente africano e do mundo.

No entanto, esta análise faz levantar as seguintes questões:

O que é que está na base deste problema? Qual é a influência que têm as políticas públicas no desenvolvimento local e das comunidades em Angola?

Numa primeira análise, pode se aferir que, a problemática do desenvolvimento local em Angola está intrinsecamente ligada ao tipo de políticas públicas que os governos, quer a nível central, provincial, municipal, distrital ou comunal traçam. Por outra, podese aludir ao tipo de liderança dos governantes, pois, apesar de se dizer que Angola está em franco crescimento económico, tem uma economia pouco diversificada em que o sector petrolífero representa infelizmente cerca de $45 \%$ do PIB, $60 \%$ das receitas fiscais representando mais de $90 \%$ das exportações, expondo a economia do País aos choques da economia mundial.

Assim, para melhor debruçar-se desta problemática, parte-se do entendimento daquilo que se define como políticas públicas e suas tipologias na visão de vários teóricos. Posteriormente ater-se-á as políticas públicas em Angola e a questão desenvolvimento local. No terceiro capítulo aborda-se as políticas públicas e sua incidência no despovoamento das comunidades locais. Já no quarto capítulo, o estudo versa-se sobre as competências dos municípios na execução de políticas públicas. Por último são apresentadas as considerações finais e as necessárias referências bibliográficas. 


\section{REVISÃO TEÓRICA E CONCEITUAL}

\subsection{Políticas públicas}

O estudo das políticas públicas surge nos anos cinquenta do século XX como reação as grandes transformações do papel do Estado, especialmente no contexto dos Estados Unidos da América.

A função que o Estado desempenha em nossa sociedade sofreu inúmeras transformações ao passar do tempo. Actualmente é comum se afirmar que a função do Estado é promover o bem-estar da sociedade, garantir a justiça e a segurança.

Portanto, o Estado necessita desenvolver uma série de acções e actuar directamente em diferentes áreas, tais como saúde, educação, meio ambiente, agricultura, pesca, tecnologia, etc.

Para atingir resultados em diversas áreas e promover o bem-estar da sociedade, os governos se utilizam das Políticas Públicas.

Assim sendo, então o que se entende por políticas públicas? Para poder responder esta questão, atem-se nas definições dadas por Thoening e Meny, Lasswel, Dewey, Peters e Dye.

Thoening e Meny (1992, p. 89), consideram que "uma política pública é o resultado da actividade de uma autoridade investida de poder público e de autoridade governamental". Lasswel (1992) define política pública como sendo "um programa projectado de valores, fins e práticas". Ao passo que, Dewey (1927) considerara que "Políticas Públicas" se reportam à forma em que se definiam e se construíam as questões e problemas, assim como a forma como estas chegam a agenda política.

Para Peters (1986) "Políticas Públicas" são a soma das atividades dos governos, agindo diretamente ou através de delegação, coordenação de políticas públicas que influenciam a vida dos cidadãos. Ora, isso pressupõe dizer que, as Políticas Públicas são os distintos tipos de acção que pode adoptar um governo para tratar com problemas sociais ou públicos.

Nesta ordem de pensamento, Dye (1976) afere que uma política é tudo aquilo que o governo decide fazer ou não fazer, pois ela pode ser consequência de erros involuntários, de decisões deliberadas de não actuar sobre determinada questão, de bloqueios políticos nas instâncias de decisão. 


\subsubsection{Tipologia das Políticas Públicas}

No que tange a tipologia, Theodore Lowi (1972), distingui 4 tipos de políticas públicas (regulatória, distributiva, redistributiva e constitutiva).

Dentro de um processo de análise de política pública é possível recorrer as tipologias. Esta forma de classificar o conteúdo a ser analisado é bem útil, assim utilizando, no caso de um processo de política pública, actores, estilos, instituições.

\subsubsection{Política Regulatória}

Este tipo de política actua de forma a estabelecer padrões para actores públicos e privados. Ela é desenvolvida em grande parte em um ambiente pluralista predominante e para a sua aprovação é necessária uma demonstração de força entre os actores.

As políticas regulatórias concentram-se em impor obrigações sobre os cidadãos, de modos que têm efeitos directos sobre sua conduta.

A título exemplar é o que ocorre com a legislação penal que define certos comportamentos como delitos (roubos, agressões, etc.). Obrigatoriedade de escolarização até certa idade. Bem como a regulamentação de serviços de utilidade pública como a energia e telecomunicações.

\subsubsection{Política distributiva}

Uma de suas características pode ser a concentração de benefícios por algum grupo em detrimento de outro. Ou seja, estes tipos de políticas concentram-se em maior medida no estabelecimento de privilégios, benefícios a determinados sectores/segmentos da sociedade, ou a espaços geográficos concretos.

Como exemplo, a construção de uma estrada; concessão de uma subvenção para utilização de energias limpas a certas entidades que cumpram uma série de requisitos.

\subsubsection{Políticas redistributivas}

Estes tipos de políticas caracterizam-se por transferir recursos de certos grupos para outros (de determinadas classes sociais às outras). Ou seja, têm que ver com o modo como se distribui a riqueza nacional. Só para elucidar, traz-se aqui as políticas educativas, sanitárias, segurança social, etc. 


\subsubsection{Políticas constitutivas}

Estas fazem referência aquelas regras elementárias que determinam aspectos centrais da distribuição do poder como são a diferenciação entre poder executivo, legislativo e judicial, ou o estabelecimento de vários níveis de governo. A constituição representa a ferramenta central através do qual se desenvolvem este tipo de política.

\section{POLÍTICAS PÚBLICAS EM ANGOLA}

O Plano de Desenvolvimento Nacional 2018-2022 constitui uma das principais compilações de políticas públicas para Angola, contendo nele os objectivos nacionais de médio e longo prazo.

Em Angola, não basta que se identifiquem as tipologias de políticas públicas para que se possa alcançar o desenvolvimento local, mas é preciso também que as políticas sejam elaboradas na visão do cidadão, partindo assim de um modelo de baixo para cima. Isto é, as decisões políticas no processo de elaboração de políticas públicas devem ser projectadas com base nas reais necessidades da população, permitindo assim a participação da sociedade civil. Por outra, para que haja desenvolvimento é preciso que exista de antemão o modelo de crescimento. Crescimento autocentrado em recursos naturais virados para exportações pode não ensejar oportunidades de diversificação das estruturas produtivas.

Como se pode constatar, as políticas económicas usadas em Angola para promover o desenvolvimento são passivas e não engendram oportunidades para a transformação estrutural, ainda mais por se tratar de uma economia totalmente dependente da exploração do petróleo.

\subsection{Angola e a questão do Desenvolvimento}

Os desafios do desenvolvimento de Angola em contexto de globalização e mobilidade internacional da força de trabalho, impõem medidas de políticas públicas, que proporcionem aos angolanos um papel fulcral no desenvolvimento do Estado, abarcando a melhoria de qualidade de vida dos cidadãos, a inserção da juventude no mercado de trabalho, catalisando o desenvolvimento do empresariado nacional, bem como a inserção competitiva de Angola em contexto global. 
Segundo Henriques e Leandro (2007, p. 37), o desenvolvimento "compreende o conceito de crescimento, mas é mais do que simples aumento da produção de um país ou de uma comunidade".

Em termos económico, a visão mais corrente do desenvolvimento é a que identifica desenvolvimento com crescimento económico, entendido este como um aumento progressivo do volume de produção de bens e serviços de um país, reflectido em mais altos padrões de consumo. Subentende este conceito que a multiplicação dos bens se traduzirá, necessariamente, em melhor nível de vida dos cidadãos.

Conforme aferem Marconi e Lakatos (2013, p.347) sobre a problemática do desenvolvimento, estes autores escrevem o seguinte:

Para haver desenvolvimento é necessário que haja uma integração adequada dos elementos diferenciados, abrangendo as seguintes etapas: processo (qualquer transformação definida e continua que ocorre numa estrutura preexistente); segmentação (tipo intermediário entre processo e as transformações da estrutura social); transformação estrutural (surgimento de complexos de organizações e papeis qualitativamente novos); integração (elemento unificador das estruturas).

Para Angola, as políticas sociais como sendo parte integrante das políticas públicas, deverá visar, pois, e, em primeiro lugar, que o crescimento económico seja devidamente orientado numa dupla perspectiva:

a) Permitir alcançar os mais altos níveis possíveis de satisfação das necessidades fundamentais: saúde, instrução, habitação, segurança social, tempos livres;

b) Garantir o acesso progressivo de todos os grupos aos benefícios tornados possíveis pelo crescimento da economia.

Em Angola, infelizmente a distribuição da renda nacional ainda privilegia um pequeno grupo, os das elites e, em muitos casos, o poder político (governo) opta pelas políticas públicas do decidir não fazer nada para o desenvolvimento das comunidades locais. Pois conforme afere Dye (1984) “política é tudo aquilo que o governo decide fazer ou não fazer".

Todavia, para se alcançar o bem-estar social das comunidades locais e estimular o desenvolvimento, é preciso que o governo de Angola evidencie esforços nas medidas de redução e eliminação progressiva de privilégios indevidos, os quais impedem tantas vezes que se gerem sistemas de competição favoráveis ao progresso. 
As medidas até agora referidas têm um carácter correctivo. Paralelamente, há que prosseguir uma política social de incentivo ao desenvolvimento, a qual incluirá, entre outros, os aspectos seguintes: estímulo para o aparecimento de indivíduos e grupos com capacidade de empreendimento; criação de um clima favorável ao progresso, através de meios de comunicação mais controlados pelo público, capazes de se tornarem um veículo condutor do desejo de inovação e progresso e não só de retracção e imobilismo social; estímulos à selecção e formação escolar científica e técnico, aberto à inovação e ao progresso e com capacidade de comprometimento na acção.

O desenvolvimento local de uma comunidade engendrada por políticas públicas assertivas, nota-se quando se verifica progresso qualitativo dos seus membros, bem como quando são garantidas as condições basilares, tais como: emprego condignamente remunerado, distribuição justa dos rendimentos, saúde e educação, saneamento básico, estendendo-se as liberdades e garantias fundamentais aos cidadãos. Para Angola, parecenos ainda estar longe deste desiderato.

Tendo em conta o acima exposto, apesar dos esforços que têm sidos feitos pela actual liderança do país, ainda é uma quimera colocar Angola nos paradigmas dos países mais bem desenvolvidos ou de boa governação em África.

Tal como aferem Henriques e Leandro (2007, p. 46), medir o desenvolvimento comunitário ou local "exigem indicadores de ordem sociocultural e até mesmo político, como por exemplo: número de habitantes por médico, taxa de alfabetização, número de jornais editados, taxa de participação eleitoral".

Todavia, o valor destas comparações reside sobretudo em permitir evidenciar, por um lado, que o crescimento económico não conduz só por uma melhor escolaridade, melhor saúde e melhor nível de satisfação em geral, pois que se podem encontrar desequilíbrios na posição relativa de um país face a outros, de harmonia com os vários tipos de indicadores. 


\section{POLÍTICAS PÚBLICAS E SUA INCIDÊNCIA NO DESPOVOAMENTO DAS COMUNIDADES LOCAIS}

A busca de melhores condições de vida, especialmente da zona rural para urbana, tem sido motivada por vários factores inerentes aos tipos de políticas públicas, mais concretamente para as políticas sociais, e tem estado na base do despovoamento das comunidades rurais, provocando assim um grande aglomerado nos centros urbanos.

Com base em Vila Nova (1999, p. 199), para além dos factores geográficos, “o estilo de liderança comunitária, questões religiosas e ideológicas" podem ser preponderantes para o êxodo rural, bem como a elaboração e execução das políticas públicas.

Angola é um estado com uma população que vive maioritariamente na zona rural, dedicada ao cultivo do campo, embora se trate de uma agricultura de subsistência e com um elevado índice de analfabetismo. O fraco investimento por parte do poder público nestas zonas, faz com que a população do interior, na procura dos serviços basilares, emigre da zona rural para a zona urbana. Este fenómeno faz com que haja uma superlotação nas cidades, criando, no entanto, fortes problemas sociais, tal é o caso do saneamento básico.

Num estudo realizado com os estudantes do $3^{\circ}$ ano do Curso de Sociologia, variante Comunitária (2019), na disciplina de Sociologia Política, bem como os estudantes do $1^{\circ}$ ano do Curso de Gestão e Administração Pública (2020), na disciplina de Políticas Públicas, da Escola Superior Politécnica de Malanje, aonde como principal foco era aferir a influência das políticas públicas no desenvolvimento local e sua incidência no despovoamento das comunidades rurais, foi possível constatar o seguinte:

1. O despovoamento das comunidades locais e rurais em Angola em geral, e particularmente na Província de Malanje, está associada a fraca intervenção do Governo em criar condições de infra-estruturas, tal é o caso das vias de acesso, que como se sabe, desempenham um papel de extrema importância para o desenvolvimento de qualquer comunidade.

Todavia, o mau estado das vias de acesso em todo país e principalmente das comunidades mais recônditas, tem retraído o crescimento e desenvolvimento da economia, uma vez que, as comunidades que se dedicam a agricultura e comércio, se vê 
dificultadas em escoar o produto da periferia para os centros urbanos, e concomitantemente ter acesso a outros bens, tais como: sal, peixe salgado, óleo vegetal, sabão, roupas entre outros bens de primeira necessidade.

2. Outro factor que merece atenção tem a ver com as políticas viradas ao ensino, desde o primário, secundário ao ensino superior. O número reduzido de escolas, bem como a fraca extensão do ensino médio e superior, associado ao ensino de qualidade, motivou e tem motivado a uma frangia da sociedade que vive no interior, deixar estas zonas para ir a busca de melhor ensino nos centros urbanos.

Do acima exposto, alude-se que, por razões associadas as políticas de ensino, muitos quadros são obrigados a deixarem as suas comunidades com o propósito de dar continuidade a formação académica ou técnico profissional, levando ao despovoamento massivo de muitas comunidades.

Acha-se que, não baste que a autoridade governamental trace políticas públicas se elas não tiverem um impacto real na vida dos cidadãos a que se destina, mas é preciso que elas respondam as reais necessidades e específicas de cada comunidade. Assim sendo, no processo de elaboração, definição e agendamento de qualquer política social, carece a auscultação do cidadão a que se destina, pois, em muitas situações, se tem verificado um desperdício de meios monetários e de infraestruturas que não respondem realmente as expectativas dos destinatários.

Fruto de algumas viagens feita no interior de Angola, assim como o diálogo mantido com algumas autoridades tradicionais, foi possível constatar muita prática de má gestão dos fundos públicos por parte de certas autoridades governamentais. A título ilustrativo, são os vários hospitais e escolas espalhadas por Angola toda, sem quase o mínimo de condições criadas para o seu funcionamento, associado a falta de quadros que possam exercer as actividades pelas quais estas infraestruturas foram construídas.

1. Políticas de empregabilidade. A criação deficitária de postos de trabalho no interior das comunidades, associada a uma política segregacionista na construção e igualdade de oportunidades para os jovens, pode estar na base para muitos deixarem a periferia e emigrarem para os centros urbanos. 
Ora, o desemprego nas comunidades locais, motivadas por fracas ou inexistência de políticas de empregabilidade, constitui, de facto, um dos grandes factores naquilo que sociólogos, demógrafos, geógrafos e outros especialistas das ciências sociais denominam de êxodo rural. Este fenómeno tem maior incidência na camada juvenil, que representa a maior parte da população angolana, de modos particular as comunidades afecta a Província de Malanje.

O estudo permitiu aferir que, o baixo número de postos de trabalhos não só tem maior incidência na função pública, mas também no sector empresarial.

Nota-se igualmente que, para a realidade angolana, o Estado continua a ser o maior empregador, isto porque há um fraco incentivo para o sector empresarial bem como para o empreendedorismo. Fruto disso, os jovens não saem apenas do interior do país para dar continuidade dos estudos, mas também em busca do emprego ou de melhores condições de empregabilidade, com salários mais ou menos condignos.

Acha-se que, estes factores elencados têm uma grande relação com as políticas públicas, ou seja, com o tipo de políticas elaboradas e que garantam o desenvolvimento das comunidades locais. Conforme anteriormente referiu-se, não baste que se criem políticas públicas a nível central, mas é preciso que, no processo de elaboração das mesmas políticas se inclua o cidadão. Isto quer dizer que, antes da implementação de qualquer programa de governação, se possa, de acordo com um processo de auscultação, aferir quais são as reais necessidades de cada comunidade, tendo sempre em conta as especificidades de cada povo.

Porém, isso leva a reflectir a necessidade de se avaliar as políticas públicas que têm sido implementadas pelas entidades governamentais de Angola. De maneira geral, o processo de avaliação de uma política leva em conta seus impactos e funções cumpridas pela política. Por outra, busca determinar sua relevância, analisar a eficiência, eficácia e sustentabilidade das acções desenvolvidas, bem como servir como um meio de aprendizado para os actores públicos.

Os impactos de uma política pública se referem aos efeitos que determinada política pública provoca na capacidade de cada actor e grupos sociais, por meio da redistribuição de recursos e valores, afectando interesses e suas estruturas de preferência. 
Tal como Simões, Rocha, Santos e Carvalho (2008, p.19), idealmente uma boa política deve cumprir as seguintes funções:

- Promover e melhorar os níveis de cooperação entre os actores envolvidos;

- Constituir-se num programa factível, isto é implementável,

- Reduzir a incerteza sobre as consequências das escolhas feitas,

- Evitar o deslocamento da solução de um problema político por meio da transferência ou adiamento para outra arena, momento ou grupo,

- Ampliar as opções políticas futuras e não presumir valores dominantes e interesses futuros nem predizer a evolução dos conhecimentos. Uma boa política deveria evitar fechar possíveis alternativas de acção.

A avaliação é um passo importante no processo de elaboração de políticas públicas, pois, ela permitirá a decisor político aferir a eficiência e eficácia do programa que se pretende implementar.

Todavia, para se analisar a eficácia e eficiência de um determinado programa, uma avaliação deve buscar responder se os produtos alcançados são gerados em tempo hábil, se os custos para tais produtos são os menores possíveis e se esses produtos atendem aos objectivos da política.

Uma boa política deve ser sustentável. De facto, a sustentabilidade da política consiste na capacidade de que seus efeitos positivos se mantenham após o término das acções governamentais na área do foco da política pública.

\section{COMPETÊNCIA DOS MUNICÍPIOS NA EXECUÇÃO DE POLÍTICAS PÚBLICAS}

A Administração e Governação Local constitui uma das fórmulas institucionais do exercício do poder de autoridade do Estado nos sistemas democráticos modernos, tal é o caso de Angola. A Constituição da República de Angola consagra no que concerne a Administração Local do Estado, no seu artigo 201. ${ }^{\circ}$, o seu exercício por órgãos desconcentrados da Administração Central, como propósito de assegurar a nível local, a realização de atribuições e interesses específicos da Administração do Estado na respectiva circunscrição administrativa, respeitando a autonomia do poder local. 
De acordo com Pulson citado por Teixeira (2018, p.19), referenciando o artigo $44^{\circ}$ da Lei n⿳0十17/10 da Organização e do Funcionamento dos Órgãos de Administração Local do Estado, escreve o seguinte:

Cabe a Administração Municipal, promover e orientar o desenvolvimento socioeconómico, com base nos princípios e nas opções estratégicas definidos pelo titular do Poder Executivo e no Plano Nacional, bem como assegurar a prestação dos serviços públicos na respectiva área geográfica.

Em síntese, compete a Administração Municipal tarefas inerentes ao domínio do planeamento e do orçamento, ao desenvolvimento urbano e ordenamento do território, ao desenvolvimento económico e social, no domínio da agricultura e desenvolvimento rural, ordem interna e polícia, no domínio do saneamento básico e do equipamento rural e urbano, bem como na coordenação institucional.

Assim, percebe-se que, são várias as competências que os municípios compartilham, todos potencialmente alvo de políticas públicas, conforme abaixo é descrito:

1. Cuidar da saúde pública, assistência, protecção e garantia da pessoa portadora de deficiência;

2. Protecção do património cultural e outros bens de valores históricos,

3. Elaboração de políticas que proporcionem meios de acesso à cultura, educação e à ciência;

4. Protecção do meio ambiente, combate a poluição e qualquer de suas formas;

5. Fomentar a produção agrícola, pecuária e abastecimento alimentar;

6. Promover a política de habitabilidade, criando condições para a melhoria de moradias e saneamento básico;

7. Combater a fome e a pobreza nas suas variadas formas, a marginalização, promovendo desta forma a integração social dos sectores mais desfavorecidos.

Os estudos recentes relativos as Políticas Públicas apontam para a descentralização como uma forma de torna-las mais eficientes e eficazes. Dito de outra forma, as políticas públicas devem ser desenvolvidas não só pela Administração Central do Estado, mas sim pelo ente municipal e local que se encontra mais próximo dos cidadãos. 
Para um município ser capaz de criar e gerenciar políticas públicas de qualidade é necessário, além dos recursos financeiros, planeamento de longo prazo. Ou seja, é importante que os actores políticos definam um objectivo e o melhor caminho para alcança-lo. Isso facilitará a elaboração e execução das políticas, bem como permitirá uma integração entre elas, evitando acções contraditórias por parte da administração.

Mas o planeamento de longo prazo, exige por parte de quem administra, a elaboração de um plano estratégico e um plano de actividades, de modos a dar um destino certo ao Orçamento Geral do Estado.

O Plano Estratégico é o documento onde se definem as estratégias de médio e longo prazo. Ele deve ser um documento dinâmico, e que reflecte a aprendizagem gerada pela elaboração do plano de actividades, da monitorização, do relatório de actividades e de outros impactos importantes que venham a ter lugar ao longo da sua execução. No entanto, o Plano Estratégico é um documento cuja responsabilidade da produção é da liderança de topo do município, pois planear é prever a curto, médio e longo prazos, metas objectivas e recursos.

Já o Plano de Actividades é um documento de muita importância na gestão dos negócios públicos com um horizonte temporal de um ano, que define os objectivos a atingir e a estratégia a seguir, hierarquizando iniciativas, programando acções e mobilizando recursos.

\section{CONSIDERAÇÕES FINAIS}

O desenvolvimento das comunidades locais em Angola, e de forma particular da Província de Malanje, depende não só do tipo de liderança, mas também do tipo de políticas públicas que são elaboradas. Além disso, há uma necessidade de se rever o modelo de elaboração das referidas políticas, tal como foi referido neste artigo, que seja um modelo inclusivo, capaz de responder as reais necessidades dos cidadãos.

Foi também possível entender que o fraco investimento nas comunidades locais, concorre para o despovoamento das mesmas e, por conseguinte, o superpovoamento dos centros urbanos, acarretando consigo graves problemas de saneamento básico e outras calamidades. 
Todavia, para que as políticas tenham eficiência e eficácia é preciso que, o processo de planeamento na execução de políticas públicas deve ser feito pelos actores políticos, mas com o auxílio dos servidores públicos e sectores da sociedade civil organizada.

A necessidade de se ouvir a opinião dos servidores se dá por questões técnicas, uma vez que eles irão operacionalizar as acções, além de que possuem informações necessárias para o melhor planeamento. Já a sociedade civil contribui com a qualidade das acções, uma vez que o elaborador poderá perceber quais são os problemas que no momento mais afligem a população de forma mais detalhada, permitindo assim traçar acções mais efectivas.

Por conseguinte, as políticas municipais ou, dito de outra forma, a municipalização dos serviços públicos é a melhor estratégia para a solução dos problemas sociais que assolam as comunidades locais. Considerando que o poder local é a esfera administrativa mais próxima do cidadão, esta tarefa se torna mais fácil. Contudo, esta constitui uma das maiores vantagens das políticas municipais, sua proximidade com o público-alvo, além disso, essa forma de construção garante maior eficiência e eficácia das acções governamentais.

\section{REFERÊNCIAS BIBLIOGRÁFICAS}

Chaques, L. (2004). Redes de Políticas Públicas. Madrid: Centro de Investigaciones Sociológica (CIS).

Constituição da República de Angola (2010). Disponível em: https://imgs.sapo.pt/jornaldeangola/content/pdf/CONSTITUICAOAPROVADA_4.2.2010-RUI-FINALISSIMA.pdf

Dye, T. (1976). Policy Analysis. Alabama: University of Alabama Press.

Evans, P. (1996). El Estado como problema y como solución. Desarrollo Económico. Revista de Ciencias Sociales, 35(140), 529-562. 
Faria, F. P. (2019). Material de Apoio: Módulo de Políticas Públicas. Luanda: Centro de Pesquisa em Políticas Públicas e Governação Local, FDUAN-Angola.

Henriques, L. S., \& Leandro, M. (2007). Introdução à Economia. Porto: Porto Editora

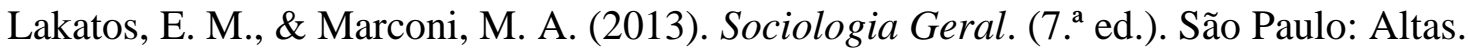
Lowi, T. (1972). Four Systems of Policy, Politics and Choice. Public Administration Review, 32(4), 298-310.

Meny,Y., \& Thoening, J. C. (1992). Las Políticas Públicas. Barcelona: Editorial Ariel.

Nova, V. (1999). Material de Apoio da disciplina de Sociologia Política. ESPM-Angola.

Peters, B. G. (1986). American Public Policy. Chatham, N. J.: Chatham House.

Simões, R., Rocha, A. M., Santos, L. M. H. P., \& Carvalho, M. C. (2008). Políticas Públicas: conceitos e práticas. Belo Horizonte: Sebrae/MG.

Teixeira, C., Camango, C., Calei, A. T. et al. (2018). Visão Estratégica de Recursos Humanos: Política de quadros e o desempenho do serviço público em Angola. Revista $n^{\circ} 4$, Centro de Pesquisa em Políticas Públicas e Governação Local, Luanda-Angola. 